\title{
Growth rate and locomotor performance trade-off is not universal in birds
}

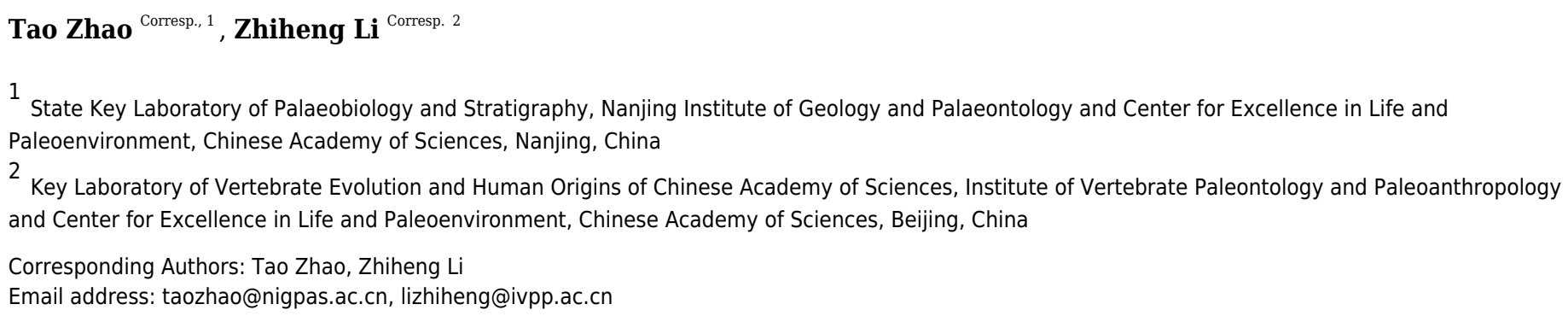

Though a trade-off between growth rate and locomotor performance has been proposed, empirical data on this relationship are still limited. Here we statistically analyze the associations of growth rate and flight ability in birds by assessing how growth rate is correlated with three wing parameters of birds: flight muscle ratio, wing aspect ratio, and wing loading. We find that fast-growing birds tended to have higher flight muscle ratios and higher wing loading than slow-growing birds, which suggests that fast-growing birds may have better takeoff performance, but lower efficiency in maneuvering flight. Accordingly, our findings suggest that the relationship between growth rate and flight ability is more complex than a simple tradeoff. Since the hindlimbs also contribute greatly to the locomotion of birds, future investigations on the relationship between growth rate and hindlimb performance will provide more insight into the evolution of birds. 
1 Growth rate and locomotor performance trade-off is not

2

3

4

5

6

7 Palaeontology and Center for Excellence in Life and Paleoenvironment, Chinese Academy of

8 Sciences, Nanjing, China

92 Key Laboratory of Vertebrate Evolution and Human Origins of Chinese Academy of Sciences,

Institute of Vertebrate Paleontology and Paleoanthropology and Center for Excellence in Life

11 and Paleoenvironment, Chinese Academy of Sciences, Beijing, China

12

13 Authors for correspondence:

14

Tao Zhao: taozhao@nigpas.ac.cn

15 Zhiheng Li: lizhiheng@ivpp.ac.cn

16

17

18

19

20

\author{
Tao Zhao ${ }^{1}$, Zhiheng $\mathrm{Li}^{2}$
}

\section{universal in birds}




\section{Abstract}

23 Though a trade-off between growth rate and locomotor performance has been proposed,

24 empirical data on this relationship are still limited. Here we statistically analyze the associations

25 of growth rate and flight ability in birds by assessing how growth rate is correlated with three

26 wing parameters of birds: flight muscle ratio, wing aspect ratio, and wing loading. We find that

27 fast-growing birds tended to have higher flight muscle ratios and higher wing loading than slow-

28 growing birds, which suggests that fast-growing birds may have better takeoff performance, but

29 lower efficiency in maneuvering flight. Accordingly, our findings suggest that the relationship

30 between growth rate and flight ability is more complex than a simple tradeoff. Since the

31 hindlimbs also contribute greatly to the locomotion of birds, future investigations on the

32 relationship between growth rate and hindlimb performance will provide more insight into the

33 evolution of birds.

34 Key words: birds, growth rate, flight ability, flight muscles, wing span, wing area, wing aspect

35 ratio 


\section{Introduction}

43 Growth rates vary considerably among different taxa and organisms (e.g., Arendt 1997; Case

44 1978; Ricklefs 1973; Ricklefs 1968). It has been suggested that the growth rate for an organism

45 results from a compromise between benefits and costs of rapid growth within physiological

46 constraints (Arendt 1997; Dmitriew 2011). Rapid growth allows organisms to shorten the

47 duration of reaching maturity when they are vulnerable to predators (Case 1978). However, rapid

48 growth may reduce longevity (Gabriela 2018; Metcalfe \& Monaghan 2003) and reduce

49 investment in other functions, because overall resources are limited (Arendt 1997; Dmitriew

50 2011; Martin et al. 2011). One of the main functions that are suggested to be negatively affected

51 by rapid growth is locomotor performance (e.g., Billerbeck et al. 2001; Dmitriew 2011; Lee et al.

52 2010). For example, Billerbeck et al. (2001) showed that within the Atlantic silversides (Menidia

53 menida), the fast-growing fish have lower maximum prolonged and burst swimming speeds than

54 slow-growing ones.

56 Birds are ideal for testing factors that are suggested to influence growth rate, because previous

57 studies have accumulated relatively abundant data (Martin 2004; Remeš \& Martin 2002; Starck

$58 \&$ Ricklefs 1998). By far, the variations of growth rate in birds has been found to be associated

59 with a suite of factors. Growth rate is inversely correlated with body mass, and precocial birds

60 tend to grow faster than altricial birds (Ricklefs 1973). Royle et al. (1999) suggested that growth 
61 rate is associated with sibling competition. Several studies on passerines have shown that growth

62 rates increase with nest predation rates (Cheng \& Martin 2012; Martin et al. 2011; Remeš \&

63 Martin 2002). Sandvig et al. (2019) found that birds from high latitudes tend to grow faster than

64 birds from lower latitudes, and that birds nesting in open nests grow faster than birds nesting in enclosed nests. An inverse relationship between growth rate and locomotor performance at the interspecific level has also been proposed for songbirds (Martin 2015). However, contradictory

67 evidence exists at the intraspecific level. For example, Coslovsky \& Richner (2011) found that

68 within great tits (Parus major), the nestlings that grow faster tend to have longer wings at

69 maturity. Moreover, statistical tests on the relationship between growth rate and locomotor

70 performance in birds at the interspecific level are still lacking.

72 Here we empirically assess how growth rate is associated with three wing parameters of birds:

73 flight muscle ratio, wing aspect ratio, and wing loading. Flight muscles mass is important in

74 determining the power that flight muscles can produce (Pennycuick 2008). Wing loading and

75 aspect ratio are key parameters for the aerodynamics of flight, which can be calculated based on

76 body mass, wing span and wing area (Pennycuick 2008).

Materials \& Methods 
82 Two datasets were compiled: one (81 species) to assess the relationship between growth rate and

83 flight muscle ratio (Table S1), and the other (125 species) to assess the relationship between

84 growth rate and wing aspect ratio and wing loading (Table S2). Body mass, development mode

85 (precocial or altricial), nest type (open or enclosed), clutch size, latitude, and migratory status

86 (migratory or not) were included as control variables. Data on growth rate ("K" in the logistic

87 function) were taken from AnAge Database (Tacutu et al. 2013) and Tholon \& Queiroz (2007);

88 body mass and mass of flight muscles (m. pectoralis and m. supracoracoideus) from Wright et al.

89 (2016) and Viscor \& Fuster (1987); body mass, wing span and wing area from Pennycuick

90 (2008) and Serrano et al. (2016); development mode from Starck \& Ricklefs (1998); clutch size

91 from Myhrvold et al. (2015); nest type from Sibly et al. (2012) and Harrison \& Greensmith

92 (1993); latitude from BirdLife International and Handbook of the Birds of the World (2018);

93 migratory status from BirdLife International (2019). Data on body mass were taken from

94 different sources for different sets of species. Flight muscles ratio was calculated as mass of

95 flight muscles divided by body mass; aspect ratio as wing span squared divided by wing area;

96 wing loading as body mass divided by wing area.

\section{Data analysis}

100 Nine models were tested in total. Three models were tested to assess the relationship between 
101 growth rate and three wing parameters (flight muscle ratio, wing aspect ratio, and wing loading),

102 respectively, while controlling for body mass, development mode, clutch size, nest type, latitude,

103 and migratory status. Another three models were tested to assess the relationship between

104 latitude and these three wing parameters, respectively, while controlling for body mass,

105 development mode, clutch size, nest type, and migratory status. The last three models were tested

106 to assess the relationship between growth rate and these three wing parameters, respectively,

107 while controlling for body mass, development mode, clutch size, nest type, and migratory status,

108 with latitude dropped.

109

110 All analyses were carried out in R (R Core Team 2019) using the packages "ape" (Paradis et al.

111 2004), "caper" (Orme et al. 2018) and phytools (Revell 2012). To account for phylogeny, we

112 used 1000 time-calibrated phylogenetic trees from birdtree.org (Jetz et al. 2012) for each dataset

113 in our study, from which a majority rule consensus tree was derived using the function

114 "consensus.edges" in the package "phytools". The phylogenetic generalized least squares

115 (PGLS) analyses with Pagel's $\lambda$ were performed using the function "pgls" in the package

116 "caper". Before analyses, growth rate, body mass, flight muscle ratio, wing aspect ratio, wing

117 loading, and clutch size were $\log 10$-transformed, while the absolute values of latitude were used.

118 The effect size "r" (for continuous variables) or "Hedges' d" (for categorical variables) was

119 calculated from t-values obtained from PGLS models (Nakagawa \& Cuthill 2007). 
121 To visualize the relationship between growth rate and wing parameters, residuals of these

122 variables were obtained by regressing them against the control variables.

123

124 Results

125

126 In order to assess the relationship between growth rate and wing parameters, we tested 9 models

127 (Tables $1-3$ ). There are phylogenetic signals in all these models, indicating that the

128 phylogenetic non-independence should be accounted for in these analyses.

130 When controlling for body mass, development mode, clutch size, nest type, latitude, and

131 migratory status, among the three wing parameters, only flight muscle ratio was significantly

132 correlated with growth rate $(\mathrm{P}=0.007$, effect size $=0.31)$, while wing aspect ratio $(\mathrm{P}=0.593$,

133 effect size $=-0.05)$ and wing loading $(\mathrm{P}=0.090$, effect size $=0.16)$ were not $($ Models $1-3$ in

134 Table 1). Birds with higher flight muscle ratios tended to grow faster than birds with smaller

135 flight muscle ratios (Fig. 1). In all these three models, latitude was significantly correlated with

136 growth rate $(\mathrm{P}=0.032$, effect size $=0.25$ in model $1 ; \mathrm{P}=0.001$, effect size $=0.29$ in $\operatorname{model} 2 ; \mathrm{P}$

$137=0.002$, effect size $=0.28$ in model 3); birds from higher latitudes tended to grow faster than

138 birds from lower latitudes.

140 Latitude was significantly correlated with wing aspect ratio $(\mathrm{P}=0.010$, effect size $=-0.23)$ and 
141 wing loading $(\mathrm{P}=0.041$, effect size $=0.19)$, but not with flight muscle ratio $(\mathrm{P}=0.315$, effect

142 size $=0.12$, when controlling for body mass, development, clutch size, nest type, and migratory

143 status (Models $4-6$ in Table 2).

144

145 After dropping latitude from the models, growth rate was significantly correlated with mass of

146 flight muscle ratio $(\mathrm{P}=0.006$, effect size $=0.31)$ and wing loading $(\mathrm{P}=0.028$, effect size $=0.20$,

147 Fig. 1), but not with wing aspect ratio $(\mathrm{P}=0.237$, effect size $=-0.11)$ (Models $7-9$ in Table 3).

148 Fast-growing birds tended to have higher flight muscle ratios and higher wing loadings than

149 slow-growing birds.

150

151 Discussion

152

153 Our results show that fast-growing birds tended to have larger flight muscle ratios and larger wing loadings than slow-growing birds, which suggests that the relationship between growth rate and flight ability in birds is more complex than a simple tradeoff. It has been shown that the takeoff ability of birds is largely dependent on flight muscle ratio (Hartman 1961; Marden 1987).

157 Birds with higher flight muscle ratios can provide larger mass-specific lift force and take off more steeply than birds with lower flight muscle ratios. The positive correlation between growth rate and flight muscle ratio suggests that fast-growing birds tend to have better escape performance from predators than slow-growing birds. In the fixed-wing model of maneuvering 
161 performance, the radius of turn is proportional to wing loading; that is, birds with lower wing

162 loading can make turns of smaller radii (Norberg et al. 1971; Norberg 1990; Pennycuick 2008).

163 However, it has been suggested that birds with high wing loading can also effect turns of small

164 radii, but requiring slowing and flapping, which is energetically more expensive (Warrick et al.

165 1998; Warrick et al. 2002). In other words, wing loading is associated with efficiency of

166 maneuvering flight (Warrick et al. 2002). The positive correlation between growth rate and wing

167 loading suggests fast growth of birds may negatively affect the efficiency of maneuvering flight.

168 Aspect ratio reflects the efficiency of flight; an increase of aspect ratio can increase the lift and

169 reduce the drag (Norberg 1990; Pennycuick 2008). The lack of significant correlation between

170 growth rate and aspect ratio suggests that growth rate and efficiency of flight are likely to be

171 disconnected.

172

173 While the tradeoff caused by limited resources can explain growth rate's negative associations

174 with wing areas (birds with smaller wing areas have higher wing loading), the mechanisms

175 underlying the positive correlation between growth rate and the size of flight muscles remains to

176 be explored. Wright et al. (2016) showed that islands birds tend to evolve smaller flight muscles

177 and found a positive correlation between the size of flight muscles and predation pressure, when

178 using raptorial species richness and the presence of mammalian predators as proxies for

179 predation pressure. Sandvig et al. (2019) showed that among altricial birds, island birds tend to

180 grow slower than continental birds, though the relationship is marginally non-significant. A 
181 positive correlation between growth rate and nest predation rate has been demonstrated in

182 previous studies of passerines (Cheng \& Martin 2012; Martin et al. 2011; Remeš \& Martin

183 2002). These studies suggest that predation pressure can be a potential factor that drives the

184 correlated evolution of growth rate and the size of flight muscles in birds.

186 The positive relationship found between growth rate and latitude is consistent with previous

187 studies (e.g., Martin 2015; McCarty 2001; Ricklefs 1968; Ricklefs 1976; Sandvig et al. 2019).

188 Moreover, latitude may confound growth rate's associations with wing loading. Martin (2015)

189 suggested that the slower growth of tropical birds is associated with enhanced flight performance

190 after fledging than temperate birds. The positive association of latitude with wing loading and

191 the negative association of latitude with wing aspect ratio suggest that tropical birds may be

192 more efficient in maneuvering flight and flight in general.

193

194 In extant birds, the sternal keel serves as the attachment of flight muscles (i.e., m.

195 supracoracoideus and $\mathrm{m}$. pectoralis) and the sternal keel length is positively correlated with flight

196 muscle mass (Wright et al. 2016). By contrast, in the earliest fossil birds, for example,

197 Archaeopteryx, an ossified sternal keel is absent (Zheng et al. 2014), and an enlargement of the

198 sternal keel along the lineage leading to crown birds has been well documented (O'Connor et al.

199 2015b; Zheng et al. 2014; Zheng et al. 2012). However, how the absence or the small size of the

200 sternal keel in early birds could affect the size of flight muscles remain to be elucidated (Mayr 
201 2017; O'Connor et al. 2015a; Olson \& Feduccia 1979). Recent prolific studies suggest that

202 growth rates of extinct taxa can be estimated from their bone histology (Cubo et al. 2012;

203 Erickson 2005; Erickson 2014; Erickson et al. 2009; Erickson et al. 2001; Padian et al. 2001).

204 Accordingly, our finding of the positive correlation between growth rate and the size of flight

205 muscles suggests that bone microstructures may also be associated with the size of flight

206 muscles. Further investigations on the relationship between bone histology and the size of flight

207 muscles, and possibly other flight-related parameters, may provide a new avenue to

208 understanding the early evolution of flight and change in growth rate.

210 Conclusions

212 Our study shows that growth rate and flight ability are correlated in avian evolution, and their

213 relationship is more complex than a simple tradeoff as proposed in previous studies. Fast-

214 growing birds tended to have higher flight muscle ratios and lower wing loading, which means

215 that fast-growing birds may have better takeoff performance, but lower efficiency in

216 maneuvering flight. Besides wings, legs contribute greatly to the locomotion of birds and are

217 important for birds to occupy different habitats (Habib \& Ruff 2008; Stoessel et al. 2013; Zeffer

218 et al. 2003). Moreover, wings and legs are highly linked during avian evolution (Allen et al.

219 2013; Heers \& Dial 2015; Zhao et al. 2017). Further studies on the relationship between growth

220 rate and hindlimb performance will provide more insights into the evolution of birds. 


\section{Acknowledgements}

223 We are grateful to Prof. Zhonghe Zhou for discussion and Dr. Zhenchao Wang for help with 224 ArcGIS.

225

226 References

Allen V, Bates KT, Li Z, and Hutchinson JR. 2013. Linking the evolution of body shape and locomotor biomechanics in bird-line archosaurs. Nature 497:104-107. 10.1038/nature12059

Arendt JD. 1997. Adaptive intrinsic growth rates: an integration across taxa. The Quarterly

Billerbeck JM, Lankford TE, and Conover DO. 2001. Evolution of intrinsic growth and energy acquisition rates. I. Trade-offs with swimming performance in Menidia menidia. Evolution 55:1863-1872.

BirdLife International. 2019. IUCN Red List for birds. Downloaded from http://www.birdlife.org the world. Version 2018.1. Available at http://datazone.birdlife.org/species/requestdis. terrestrial vertebrates. The Quarterly Review of Biology 53:243-282. 
241 Cheng Y-R, and Martin TE. 2012. Nest predation risk and growth strategies of passerine species: grow fast or develop traits to escape risk? The American Naturalist 180:285-295.

243 $10.1086 / 667214$

244 245

246

248

250

251

252

253

254

255

256

257

258

259

260 Functional Ecology 25:878-888. 10.1111/j.1365-2435.2011.01834.x

Cubo J, Le Roy N, Martinez-Maza C, and Montes L. 2012. Paleohistological estimation of bone growth rate in extinct archosaurs. Paleobiology 38:335-349. 10.1666/08093.1

Dmitriew CM. 2011. The evolution of growth trajectories: what limits growth rate? Biological Reviews 86:97-116.

Erickson GM. 2005. Assessing dinosaur growth patterns: a microscopic revolution. Trends Ecol Evol 20:677-684. 10.1016/j.tree.2005.08.012

Erickson GM. 2014. On dinosaur growth. Annual Review of Earth and Planetary Sciences 42:675-697.

Erickson GM, Rauhut OW, Zhou Z, Turner AH, Inouye BD, Hu D, and Norell MA. 2009. Was dinosaurian physiology inherited by birds? Reconciling slow growth in Archaeopteryx. PLoS ONE 4:e7390.

Erickson GM, Rogers KC, and Yerby SA. 2001. Dinosaurian growth patterns and rapid avian growth rates. Nature 412:429-433.

Gabriela AJ. 2018. "The Same Thing That Makes You Live Can Kill You in the End”: Exploring the Effects of Growth Rates and Longevity on Cellular Metabolic Rates and Oxidative 
262 Habib MB, and Ruff CB. 2008. The effects of locomotion on the structural characteristics of avian limb bones. Zoological Journal of the Linnean Society 153:601-624. 10.1111/j.1096-3642.2008.00402.x

Harrison C, and Greensmith A. 1993. Birds of the World. London: Dorling Kindersley.

Hartman FA. 1961. Locomotor mechanisms of birds: Smithsonian institution.

267

Heers AM, and Dial KP. 2015. Wings versus legs in the avian bauplan: development and evolution of alternative locomotor strategies. Evolution 69:305-320. 10.1111/evo.12576

Jetz W, Thomas GH, Joy JB, Hartmann K, and Mooers AO. 2012. The global diversity of birds in space and time. Nature 491:444-448.

Lee W-S, Monaghan P, and Metcalfe NB. 2010. The trade-off between growth rate and locomotor performance varies with perceived time until breeding. The Journal of Experimental Biology 213:3289. 10.1242/jeb.043083

Marden JH. 1987. Maximum lift production during takeoff in flying animals. Journal of Experimental Biology 130:235-258.

Martin TE. 2015. Age-related mortality explains life history strategies of tropical and temperate songbirds. Science 349:966-970.

Martin TE, Lloyd P, Bosque C, Barton DC, Biancucci AL, Cheng YR, and Ton R. 2011. Growth rate variation among passerine species in tropical and temperate sites: an antagonistic interaction between parental food provisioning and nest predation risk. Evolution 
$65: 1607-1622$.

282 Mayr G. 2017. Pectoral girdle morphology of Mesozoic birds and the evolution of the avian supracoracoideus muscle. Journal of Ornithology 158:859-867.

284 McCarty JP. 2001. Variation in Growth of Nestling Tree Swallows Across Multiple Temporal and Spatial Scales. The Auk 118:176-190. 10.1642/00048038(2001)118[0176:Vigont]2.0.Co;2

Metcalfe NB, and Monaghan P. 2003. Growth versus lifespan: perspectives from evolutionary ecology. Experimental Gerontology 38:935-940.

Myhrvold NP, Baldridge E, Chan B, Sivam D, Freeman DL, and Ernest SKM. 2015. An amniote life-history database to perform comparative analyses with birds, mammals, and reptiles. Ecology 96:3109-3109. doi:10.1890/15-0846R.1

Nakagawa S, and Cuthill IC. 2007. Effect size, confidence interval and statistical significance: a practical guide for biologists. Biological Reviews 82:591-605. 10.1111/j.1469185X.2007.00027.x

Norberg R, xc, ke, and Norberg UM. 1971. Take-off, landing, and flight speed during fishing flights of Gavia stellata (Pont.). Ornis Scandinavica (Scandinavian Journal of Ornithology) 2:55-67. 10.2307/3676239

Norberg U. 1990. Vertebrate flight: mechanics, physiology, morphology, ecology and evolution: Springer Berlin Heidelberg.

300 O'Connor JK, Zheng X, Wang X, Zhang X, and Zhou Z. 2015a. The gastral basket in basal birds 
and their close relatives: size and possible function. Vertebrata PalAsiatica 53:133-152.

302 O'Connor JK, Zheng XT, Sullivan C, Chuong CM, Wang XL, Li A, Wang Y, Zhang XM, and Zhou ZH. 2015b. Evolution and functional significance of derived sternal ossification patterns in ornithothoracine birds. J Evol Biol 28:1550-1567. 10.1111/jeb.12675

Olson SL, and Feduccia A. 1979. Flight capability and the pectoral girdle of Archaeopteryx.

306 Nature 278:247-248.

Orme D, Freckleton R, Thomas G, Petzoldt T, Fritz S, Isaac N, and Pearse W. 2018. caper: Comparative analyses of phylogenetics and evolution in R. R package version 1.0.1. Nature 412:405-408.

311 Paradis E, Claude J, and Strimmer K. 2004. APE: analyses of phylogenetics and evolution in R language. Bioinformatics 20:289-290. 10.1093/bioinformatics/btg412

313 Pennycuick CJ. 2008. Modelling the flying bird. Amsterdam: Elsevier.

314 R Core Team. 2019. R: A language and environment for statistical computing. 3. 5. 3 ed. Vienna, Austria: R Foundation for Statistical Computing.

316 Remeš V, and Martin TE. 2002. Environmental influences on the evolution of growth and developmental rates in passerines. Evolution 56:2505-2518.

318 Revell LJ. 2012. phytools: an R package for phylogenetic comparative biology (and other things). Methods in Ecology and Evolution 3:217-223. 10.1111/j.2041- 
321 Ricklefs R. 1973. Patterns of growth in birds. II. Growth rate and mode of development. Ibis

322 115:177-201.

323 Ricklefs RE. 1968. Patterns of growth in birds. Ibis 110:419-451. 10.1111/j.1474919X.1968.tb00058.x

325

326

327

328

329

330

331

332

333

334

335

336

337

338

339

340

$$
\text { 10.1111/j.1474-919X.1976.tb03065.x }
$$

Royle NJ, Hartley IR, Owens IPF, and Parker GA. 1999. Sibling competition and the evolution of growth rates in birds. Proceedings of the Royal Society of London Series B: Biological Sciences 266:923.

Sandvig EM, Coulson T, and Clegg SM. 2019. The effect of insularity on avian growth rates and implications for insular body size evolution. Proceedings of the Royal Society B: Biological Sciences 286:20181967.

Serrano FJ, Palmqvist P, Chiappe LM, and Sanz JL. 2016. Inferring flight parameters of Mesozoic avians through multivariate analyses of forelimb elements in their living relatives. Paleobiology:1-26. 10.1017/pab.2016.35

Sibly RM, Witt CC, Wright NA, Venditti C, Jetz W, and Brown JH. 2012. Energetics, lifestyle, and reproduction in birds. Proceedings of the National Academy of Sciences 109:10937. 10.1073/pnas.1206512109

Starck JM, and Ricklefs RE. 1998. Patterns of development: the altricial-precocial spectrum. In: Starck JM, and Ricklefs RE, eds. Avian growth and development: evolution within the 
342 Stoessel A, Kilbourne BM, and Fischer MS. 2013. Morphological integration versus ecological plasticity in the avian pelvic limb skeleton. J Morphol 274:483-495. 10.1002/jmor.20109

344 Tacutu R, Craig T, Budovsky A, Wuttke D, Lehmann G, Taranukha D, Costa J, Fraifeld VE, and de Magalhães JP. 2013. Human Ageing Genomic Resources: integrated databases and tools for the biology and genetics of ageing. Nucleic Acids Research 41:D1027-D1033. 10.1093/nar/gks1155

Tholon P, and Queiroz S. 2007. Models for the analysis of growth curves for rearing tinamous (Rhynchotus rufescens) in captivity. Brazilian Journal of Poultry Science 9:23-31.

Viscor G, and Fuster JF. 1987. Relationships between morphological parameters in birds with different flying habits. Comparative Biochemistry and Physiology Part A: Physiology 87:231-249. Warrick DR, Bundle MW, and Dial KP. 2002. Bird maneuvering flight: blurred bodies, clear heads. Integrative and Comparative Biology 42:141-148.

355 Warrick DR, Dial KP, and Biewener AA. 1998. Asymmetrical force production in the maneuvering flight of pigeons. The Auk 115:916-928. 10.2307/4089510

Wright NA, Steadman DW, and Witt CC. 2016. Predictable evolution toward flightlessness in volant island birds. Proceedings of the National Academy of Sciences 113:4765-4770. $10.1073 /$ pnas. 1522931113 
361 leg morphology in birds (Aves). Biological Journal of the Linnean Society 79:461-484.

363 Zhao T, Liu D, and Li Z. 2017. Correlated evolution of sternal keel length and ilium length in birds. PeerJ 5:e3622. 10.7717/peerj.3622

Zheng X, O'Connor JK, Wang X, Wang M, Zhang X, and Zhou Z. 2014. On the absence of sternal elements in Anchiornis (Paraves) and Sapeornis (Aves) and the complex early evolution of the avian sternum. Proceedings of the National Academy of Sciences 111:13900-13905. 10.1073/pnas.1411070111 sternum from juvenile enantiornithines. Nat Commun 3:1116. 


\section{Table $\mathbf{1}$ (on next page)}

PGLS models of growth rate in relation to flight muscle ratio (Model 1), wing aspect ratio (Model 2), and wing loading (Model 3), while controlling for body mass, development mode, clutch size, nest type, latitude, and migratory status.

Effect size "r" was calculated for continuous variables, while "Hedges" $d$ " for categorical variables. 


\begin{tabular}{|c|c|c|c|c|}
\hline & $\beta$ & $\mathrm{P}$ & $\begin{array}{c}\text { Effect size } \\
(\mathrm{r} \text { or d })\end{array}$ & $95 \%$ CI of effect size \\
\hline \multicolumn{5}{|c|}{ Model $1\left(\mathrm{R}_{\text {adjsted }}=0.53\right.$, Pagel's $\left.\lambda=0.786\right)$} \\
\hline (Intercept) & -0.58 & $<0.001$ & - & - \\
\hline Body mass & -0.24 & $<0.001$ & -0.66 & $(-0.77,-0.52)$ \\
\hline Development mode: precocial & -0.40 & $<0.001$ & -1.52 & $(-2.06,-0.99)$ \\
\hline Clutch size & -0.02 & 0.818 & -0.03 & $(-0.24,0.19)$ \\
\hline Nest type: open & $-4.37 \times 10^{-4}$ & 0.991 & $-3.31 \times 10^{-03}$ & $(-0.56,0.56)$ \\
\hline Latitude & $2.03 \times 10^{-3}$ & 0.032 & 0.25 & $(0.03,0.44)$ \\
\hline Migratory status: migratory & 0.02 & 0.530 & 0.17 & $(-0.34,0.69)$ \\
\hline Flight muscle ratio & 0.41 & 0.007 & 0.31 & $(0.10,0.49)$ \\
\hline \multicolumn{5}{|c|}{ Model $2\left(\mathrm{R}_{\text {adjsted }}^{2}=0.43\right.$, Pagel's $\left.\lambda=0.643\right)$} \\
\hline (Intercept) & -0.94 & $<0.001$ & - & - \\
\hline Body mass & -0.19 & $<0.001$ & -0.53 & $(-0.65,-0.39)$ \\
\hline Development mode: precocial & -0.29 & $<0.001$ & -0.91 & $(-1.29,-0.53)$ \\
\hline Clutch size & 0.11 & 0.147 & 0.13 & $(-0.04,0.30)$ \\
\hline Nest type: open & 0.05 & 0.116 & 0.33 & $(-0.07,0.73)$ \\
\hline Latitude & $2.86 \times 10^{-3}$ & 0.001 & 0.29 & $(0.12,0.44)$ \\
\hline Migratory status: migratory & 0.06 & 0.115 & 0.37 & $(-0.08,0.82)$ \\
\hline Aspect ratio & -0.11 & 0.593 & -0.05 & $(-0.22,0.13)$ \\
\hline \multicolumn{5}{|c|}{ Model $3\left(\mathrm{R}_{\text {adjsted }}^{2}=0.44\right.$, Pagel's $\left.\lambda=0.667\right)$} \\
\hline (Intercept) & -1.16 & $<0.001$ & - & - \\
\hline Body mass & -0.25 & $<0.001$ & -0.47 & $(-0.59,-0.32)$ \\
\hline Development mode: precocial & -0.32 & $<0.001$ & -1.00 & $(-1.38,-0.61)$ \\
\hline Clutch size & 0.13 & 0.073 & 0.16 & $(-0.01,0.33)$ \\
\hline Nest type: open & 0.05 & 0.122 & 0.32 & $(-0.07,0.72)$ \\
\hline Latitude & $2.67 \times 10^{-3}$ & 0.002 & 0.28 & $(0.11,0.43)$ \\
\hline Migratory status: migratory & 0.04 & 0.202 & 0.30 & $(-0.15,0.75)$ \\
\hline Wing loading & 0.18 & 0.090 & 0.16 & $(-0.02,0.32)$ \\
\hline
\end{tabular}




\section{Table 2 (on next page)}

PGLS models of latitude in relation to flight muscle ratio (Model 4), wing aspect ratio (Model 5), and wing loading (Model 6), while controlling for body mass, development mode, clutch size, nest type, and migratory status. 


\begin{tabular}{|c|c|c|c|c|}
\hline & $\beta$ & $\mathrm{P}$ & $\begin{array}{c}\text { Effect size } \\
(\mathrm{r} \text { or d })\end{array}$ & $95 \%$ CI of effect size \\
\hline \multicolumn{5}{|c|}{ Model $4\left(\mathrm{R}_{\text {adjsted }}=0.13\right.$, Pagel's $\left.\lambda=0.418\right)$} \\
\hline (Intercept) & 32.61 & 0.055 & - & - \\
\hline Body mass & 7.82 & 0.027 & 0.25 & $(0.04,0.45)$ \\
\hline Development mode: precocial & 7.10 & 0.257 & 0.29 & $(-0.19,0.77)$ \\
\hline Clutch size & 8.17 & 0.353 & 0.11 & $(-0.11,0.32)$ \\
\hline Nest type: open & 5.97 & 0.212 & 0.37 & $(-0.19,0.94)$ \\
\hline Migratory status: migratory & 8.39 & 0.045 & 0.55 & $(0.03,1.08)$ \\
\hline Flight muscle ratio & 17.32 & 0.315 & 0.12 & $(-0.10,0.33)$ \\
\hline \multicolumn{5}{|c|}{ Model 5 $\left(\mathrm{R}_{\text {adjsted }}=0.16\right.$, Pagel's $\left.\lambda=0.562\right)$} \\
\hline (Intercept) & 62.39 & 0.002 & - & - \\
\hline Body mass & 8.03 & 0.005 & 0.26 & $(0.08,0.41)$ \\
\hline Development mode: precocial & 14.64 & 0.015 & 0.47 & $(0.10,0.84)$ \\
\hline Clutch size & 13.18 & 0.086 & 0.16 & $(-0.02,0.32)$ \\
\hline Nest type: open & 1.09 & 0.748 & 0.07 & $(-0.33,0.46)$ \\
\hline Migratory status: migratory & 11.88 & 0.001 & 0.76 & $(0.31,1.22)$ \\
\hline Aspect ratio & -54.19 & 0.010 & -0.23 & $(-0.39,-0.06)$ \\
\hline \multicolumn{5}{|c|}{ Model $6\left(\mathrm{R}_{\text {adjsted }}^{2}=0.14\right.$, Pagel's $\left.\lambda=0.56\right)$} \\
\hline (Intercept) & 1.10 & 0.920 & - & - \\
\hline Body mass & -0.09 & 0.984 & $-1.90 \times 10^{-3}$ & $(-0.18,0.17)$ \\
\hline Development mode: precocial & 7.79 & 0.198 & 0.25 & $(-0.12,0.61)$ \\
\hline Clutch size & 19.47 & 0.009 & 0.24 & $(0.07,0.40)$ \\
\hline Nest type: open & 0.34 & 0.919 & 0.02 & $(-0.38,0.42)$ \\
\hline Migratory status: migratory & 8.25 & 0.022 & 0.54 & $(0.09,0.99)$ \\
\hline Wing loading & 22.73 & 0.041 & 0.19 & $(0.01,0.35)$ \\
\hline
\end{tabular}




\section{Table 3(on next page)}

PGLS models of latitude in relation to flight muscle ratio (Model 7), wing aspect ratio (Model 8), and wing loading (Model 9), while controlling for body mass, development mode, clutch size, nest type, and migratory status, with latitude dropped. 


\begin{tabular}{|c|c|c|c|c|}
\hline & $\beta$ & $\mathrm{P}$ & $\begin{array}{c}\text { Effect size } \\
(\mathrm{r} \text { or d) }\end{array}$ & $95 \%$ CI of effect size \\
\hline \multicolumn{5}{|c|}{ Model $7\left(\mathrm{R}_{\text {adjsted }}=0.51\right.$, Pagel's $\left.\lambda=0.792\right)$} \\
\hline (Intercept) & -0.52 & 0.001 & - & - \\
\hline Body mass & -0.22 & $<0.001$ & -0.63 & $(-0.75,-0.48)$ \\
\hline Development mode: precocial & -0.38 & $<0.001$ & -1.42 & $(-1.95,-0.89)$ \\
\hline Clutch size & $4.84 \times 10^{-4}$ & 0.995 & $7.36 \times 10^{-4}$ & $(-0.22,0.22)$ \\
\hline Nest type: open & 0.01 & 0.833 & 0.06 & $(-0.50,0.62)$ \\
\hline Migratory status: migratory & 0.04 & 0.206 & 0.35 & $(-0.17,0.86)$ \\
\hline Flight muscle ratio & 0.43 & 0.006 & 0.31 & $(0.10,0.50)$ \\
\hline \multicolumn{5}{|c|}{ Model \& $\left(\mathrm{R}_{\text {adjsted }}=0.37\right.$, Pagel's $\left.\lambda=0.717\right)$} \\
\hline (Intercept) & -0.79 & $<0.001$ & - & - \\
\hline Body mass & -0.16 & $<0.001$ & -0.46 & $(-0.59,-0.31)$ \\
\hline Development mode: precocial & -0.25 & $<0.001$ & -0.71 & $(-1.09,-0.34)$ \\
\hline Clutch size & 0.17 & 0.035 & 0.19 & $(0.02,0.36)$ \\
\hline Nest type: open & 0.05 & 0.114 & 0.33 & $(-0.07,0.73)$ \\
\hline Migratory status: migratory & 0.09 & 0.017 & 0.56 & $(0.11,1.01)$ \\
\hline Aspect ratio & -0.25 & 0.237 & -0.11 & $(-0.28,0.07)$ \\
\hline \multicolumn{5}{|c|}{ Model $9\left(\mathrm{R}_{\text {adjsted }}=0.38\right.$, Pagel's $\left.\lambda=0.733\right)$} \\
\hline (Intercept) & -1.17 & $<0.001$ & - & - \\
\hline Body mass & -0.24 & $<0.001$ & -0.44 & $(-0.57,-0.29)$ \\
\hline Development mode: precocial & -0.30 & $<0.001$ & -0.84 & $(-1.22,-0.46)$ \\
\hline Clutch size & 0.20 & 0.009 & 0.24 & $(0.06,0.40)$ \\
\hline Nest type: open & 0.05 & 0.127 & 0.32 & $(-0.08,0.72)$ \\
\hline Migratory status: migratory & 0.06 & 0.075 & 0.42 & $(-0.03,0.87)$ \\
\hline Wing loading & 0.24 & 0.028 & 0.20 & $(0.03,0.36)$ \\
\hline
\end{tabular}




\section{Figure 1}

Figure 1. Bivariate plots showing the relationships between growth rate and wing parameters in birds.

(A) residual $\log 10$ (growth rate) vs. residual $\log 10$ (flight muscle ratio); (B) residual

$\log 10$ (growth rate) vs. residual $\log 10$ (aspect ratio); (C) residual log10(growth rate) vs. residual $\log 10$ (wing loading). The lines are simple regressions between the residuals. In (A) the control variables are body mass, development mode, clutch size, nest type, latitude, and migratory status, while in (B) and (C) the control variables are body mass, development mode, clutch size, nest type, and migratory status, with latitude dropped. 


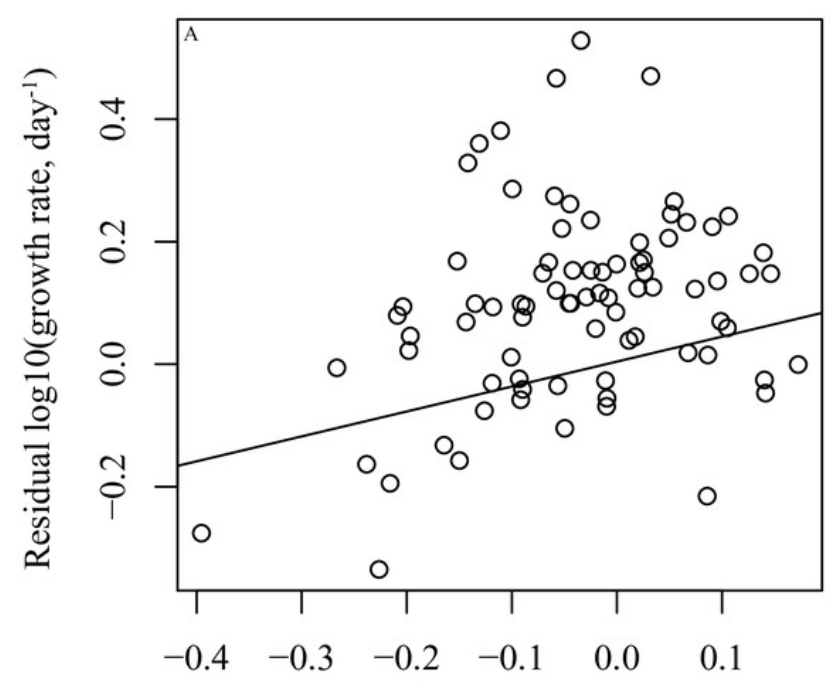

Residual $\log 10$ (flight muscle ratio)

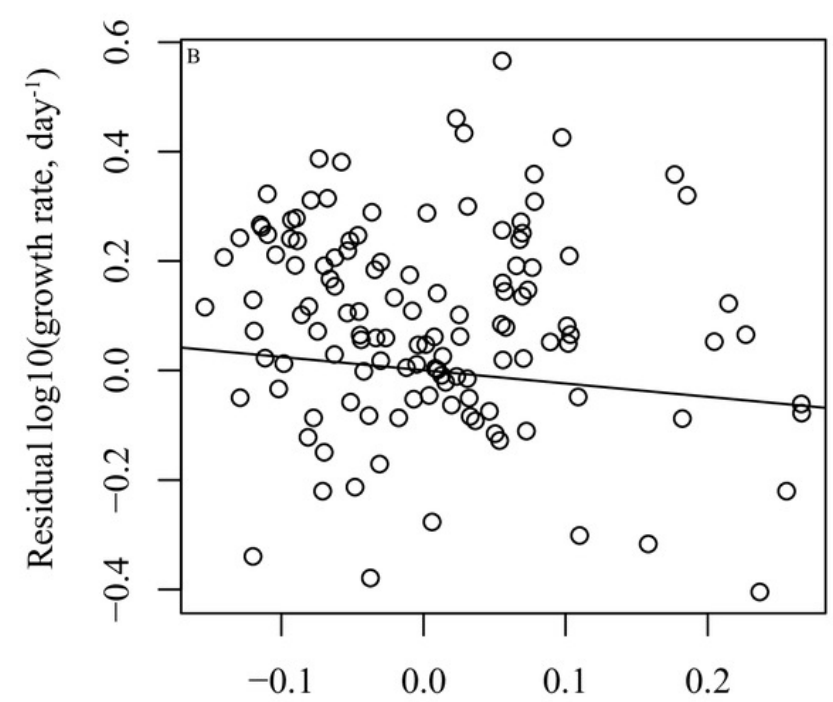

Residual $\log 10$ (aspect ratio)

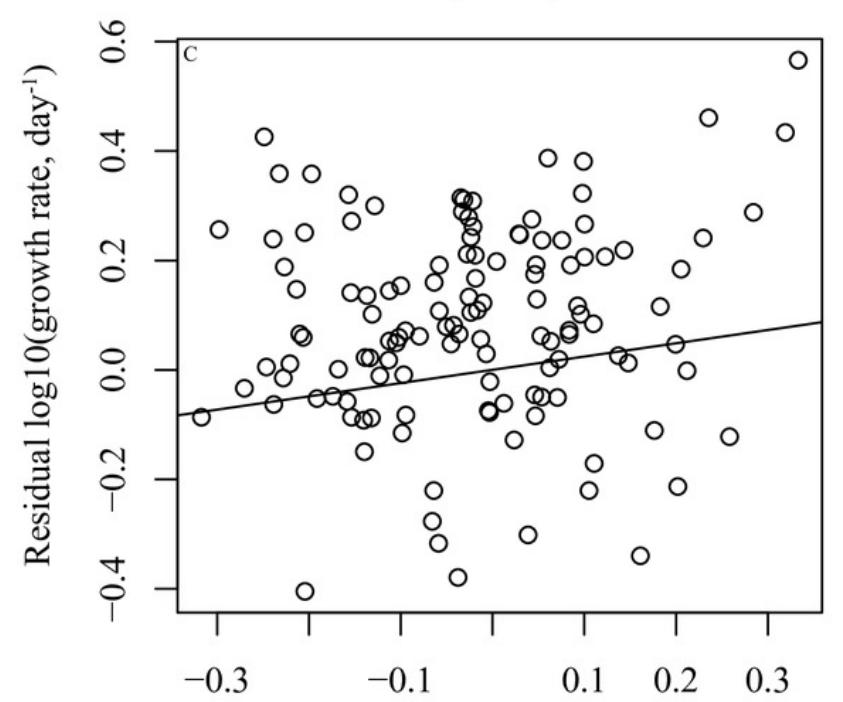

Residual $\log 10$ (wing loading, $\mathrm{kg} / \mathrm{m}^{2}$ ) 